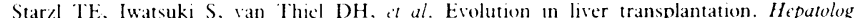
$982: 2: 61+32$

2 Rulles $K$, Williams R, Neuberger J, Catne RY. The Cambridge and King's College Hospita experience of liver transplantation. Heputology 1984:4:50-5 S.

Kumar S. Basista M, Stauber RE, et al. Orthotopic liver transplantation for alcoholic liver disease. (jastroenterolog, 1989:96:A916.

+ Brunt PW, Kew MC, Scheuer PJ, Sherlock S. Studies in alcoholic liver disease in Britain. Giu $1974 ; 15: 52-8$

Pares A, Caballeria J, Bruguera M, Torres M, Rodes J. Histological course of alcoholic hepatitis. f Hepatol 1986:2:33-42

6 Suterakis J, Resnick RH, Iber FL. Effect of alcohol abstinence on survival in cirrhotic portal hypertension. Lancel 1973;i1:65-7.

Martini GA, Teschke R. Alcohol abstinence in alcoholic liver disease. Acta Med Scand [Suppl] 1973:703:185-94

(iluud C, Henriksen SH, Nielsen G, and the Copenhagen Study (iroup for Liver Disease. Prognostic indications in alcoholic cirrhotics. Heputolog. 1988:8.222.7.

Maddrey WC, Botinou JK, Bedine MS, Weber FL, Mece E, White RI. Corticosteroid therapy of alcoholic heparits Gastroenterologe 1978:75:193-9.

alcoholic hepatitis. Gastroenterologv 1978;75.193-9. BrMed F 1985:297:708.

Oftice of Population Censuses and Survers. Mortality statistics. London: HMSO, 1986.

12 Bismuth H, Gugenheim J, Ciardullo M. Indication for hepatic transplantation in alcoholic liver cirrhosis. Transplant Proc 1986;4 (suppl 3):83-5.

\section{Functional endoscopic surgery to the sinuses}

\section{A minimally invasive treatment for sinusitis}

Endoscopy is now being used for both diagnosis and surgical treatment of disorders of the nose and paranasal sinuses. Endoscopic examination has improved our understanding of the pathological basis of chronic and recurrent sinusitis.

Direct observations of mucociliary clearance patterns have shown that there are clear cut pathways in the sinuses, with secretions always trying to leave through the natural ostia. The maxillary and frontal sinuses both drain into the nose through narrow channels in the ethmoids, an area subject to frequent anatomical variations and known as the "ostiomeatal complex."' In health these narrow clefts convey mucus into the nose with no difficulties. But if the mucosa become inflamed the pathways in the ethmoids will become obstructed and impede normal sinonasal drainage, possibly acting as a focus for recurrent or persistent inflammation, producing the clinical picture of "maxillary" or "frontal" sinusitis. "This condition can now be treated by endoscopic functional surgery, which relies on the ability of diseased sinus mucosa to recover when the source of inflammation has been removed. Clinical reports suggest that this potential reversibility may have been underestimated. ${ }^{+-6}$

The concept that the ethmoid sinuses might influence inflammatory disease in adjacent sinuses is not new, ${ }^{7}$ but our ability to visualise directly areas of mucosa and accurately image the deeper recesses of the sinuses has allowed direct confirmation of the association. ${ }^{8}$ This evidence gave a logical basis for a direct surgical approach to the ethmoids as an alternative to and possibly a replacement for the traditional radical procedures such as the Caldwell-Luc operation - at least until disease in the ostiomeatal complex area has been assessed and treated. ${ }^{9} 10$

Outpatient diagnosis in adults and children is made using $4 \mathrm{~mm}$ and $2.7 \mathrm{~mm}$ telescopes in the nose. ${ }^{112}$ Surgery is performed under either local or general anaesthesia and differs from other types of ethmoidectomy in that the procedure is carried out entirely under direct vision and an external incision is avoided. The technique is demanding and requires a detailed knowledge of ethmoid anatomy. Careful endoscopic follow up is required, but there is less of a need for $x$ ray examinations as the sinuses can be inspected directly if symptoms of disease recur.
Endoscopic sinus surgery remains a limited specialised procedure in Britain. The lack of disease classification and long term follow up has meant that there have been no controlled studies, but clinical reports of several thousand procedures from Europe and the United States show results when performed by an experienced endonasal surgeon similar to the older approaches. ${ }^{13}$ The main benefits of the technique comes from the accurate diagnosis of early disease, particularly when there is a localised cause for widespread sinus inflammatory changes. In these circumstances endoscopic surgery can be effective without the morbidity associated with traditional approaches.

CHARLES A EAST

Senior Registrar,

Ferens Institute of Otolaryngology,

University College and Middlesex School of Medicine,

London WIP 5FD

Messerklinger $W$. Uher Drainage der menschlichen nasennebenhohlen under normalen un patholegischen Bendingungẹn II Mitteilung: Die Stirnhohle und ihr Ausfurhrungssystem. Monatsschrift Ohrenheikune 1967;101:313-26.

Kinnedy DW, Zinreich SJ, Rosenbaum A, Johns $M$. Functional endoscopic sinus surgery: theory and diagnosis. Arch Otolaryngol Head and Neck Surgery 1985;111:576-82.

Stammberger H, Wolf G. Headaches and sinus disease: the endoscopic approach. Ann Otol Rhinol L.aryngol 1988:97(suppl 134):3-23.

+ Stammberger $\mathrm{H}$. Endoscopic endonasal surgery: concepts in treatment of recurring rhinosinusitis. Otolengngology 1986;94:143-56.

Albegger KW. Abnormal "hair-like" filaments in chronic maxillary sinusitis. A scanning electron microscopic investigation. Ann Otolaryngol Head and Neck Surgery 1978;220:239-49.

Wicroscopic investigation. Ann Otolaryngol Head and Neck Surgery 1978;220.239-49.

7 Proctor DF. The nose, paranasal sinuses and pharynx. In: Walters W, ed. Lewis-Walters practice of surgerv. Vol 4. Hagerstown, Maryland: Prior, 1966:1-37.

surgery. Vol 4. Hagerstown, Maryland: Prior, 1966:1-37. inreich SJ, Kennedy DW, Rosenbaum AE, Gayler BW, Kumar AJ, Stammberger H. Par

sinuses: CT imaging requirements for endoscopic surgery. Radiology 1987;163:769-75.
Stammberger H, Zinreich SJ, Kopp W, Kennedy DW, Johns ME, Rosenbaum AE. Surgical treatment of chronic recurrent sinusitis-the Caldwell-Luc versus a functional endoscopic technique. HNO 1987;35:93-105.

$10 \mathrm{Kennedy}$ DW. Functional endoscopic sinus surgery technique. Arch Otolaryngol Head and Neck Surgery 1985;111:643-49.

11 Messerklinger W. Endoscopy of the nose. Baltimore: Urban and Schwarzenburg, 1978.

12 Stammberger $\mathrm{H}$. Nasal and paranasal sinus endoscopy, a diagnostic and surgical approach to recurrent sinusitis. Endoscopy 1986;18:213-18.

13 Kennedy DW, Zinreich SJ, Shaalan H, Kuhn F, Naclerio R, Loch E. Endoscopic middle meatal antrostomy: theory, technique and patency. Laryngoscope 1987;97 (suppl 43):1-9.

\section{Adult consequences of early parental loss}

\section{Quality of care matters more than the loss itself}

Many studies show an increased risk of adult affective disorder after loss in early childhood. The studies support theories that link depression with the quality of the child's psychological response to the death or other loss of a person who is important to them. ${ }^{12}$ But the degree of risk varies from study to study, and much effort has been made to explain these variations and to decide whether it is the loss itself that constitutes the risk. It may not be.

The childhood experiences that precede depression or anxiety in adulthood ${ }^{3}$ have been identified mainly for women, ${ }^{+}$ but associations have also been found for men. ${ }^{56}$ Loss results not only from the death of a parent ${ }^{7}$ but also from separation caused, for example, by marital breakdown, hospitalisation, and wartime evacuation. ${ }^{6}$ The term "early" has been used in the studies to cover the whole of childhood up to the age of 17 . Studies have nearly always been retrospective, with possibly inaccurate data about early separations and the domestic circumstances at the time being recalled by the subjects. Adult subjects have been drawn from a wide age range (18 to over 50) of people from outpatient clinics and the general population and have shown varying degrees of 